\title{
HEPATOLOGY
}

\section{Complete response under sorafenib in patients with hepatocellular carcinoma. Relationship with dermatologic adverse events}

\begin{tabular}{|c|c|}
\hline Journal: & Hepatology \\
\hline Manuscript ID & Draft \\
\hline Wiley - Manuscript type: & Original \\
\hline Date Submitted by the Author: & $\mathrm{n} / \mathrm{a}$ \\
\hline Complete List of Authors: & $\begin{array}{l}\text { Rimola, Jordi; Hospital Clinic, Servicio de Radiodiagnóstico. Hospital Clínic } \\
\text { de Barcelona. Universitat de Barcelona, Barcelona } \\
\text { Díaz-González, Álvaro; Hospital Clinic, Liver Unit, Hospital Clínic de } \\
\text { Barcelona, IDIBAPS, CIBERehd, Universitat de Barcelona, Barcelona } \\
\text { Reig, Maria; Hospital Clinic, Liver Unit, Hospital Clínic de Barcelona, } \\
\text { IDIBAPS, CIBERehd, Universitat de Barcelona, Barcelona } \\
\text { Darnell, Anna; Hospital Clinic, Servicio de Radiodiagnóstico. Hospital Clínic } \\
\text { de Barcelona. Universitat de Barcelona, Barcelona } \\
\text { Varela, Maria; Hospital Universitario Central de Asturias, Liver Unit, } \\
\text { Hospital Universitario Central de Asturias, Oviedo. } \\
\text { Pons, Fernando; Puerta de Hierro University Hospital, Servicio de Digestivo } \\
\text { Hernandez-Guerra, Manuel; University Hospital of the Canary Islands, Liver } \\
\text { Unit } \\
\text { Delgado Blanco, Manuel; Complejo Hospitalario Universitario de A Coruña, } \\
\text { Department of Hepatology and Internal Medicine } \\
\text { Castroagudin, Javier; Hospital Clinico Universitario de Santiago de } \\
\text { Compostela } \\
\text { Matilla, Ana; Hospital General Universitario Gregorio Maranon } \\
\text { Sangro, Bruno; Clinica Universitaria, Liver Unit } \\
\text { Rodríguez de Lope, Carlos; Hospital Universitario Marques de Valdecilla } \\
\text { Sala, Margarita; Hospital Universitari Germans Trias i Pujol } \\
\text { González, Carmen; Consorci Hospital General Universitari de Valencia, } \\
\text { Servicio de Digestivo Sección Hepatologia Hospital General Universitario } \\
\text { Valencia,Valencia } \\
\text { Huertas, Carlos; Hospital Universitari de Girona Doctor Josep Trueta } \\
\text { Minguez, Beatriz; Hospital Vall d'Hebron, Hospital Universitari Vall } \\
\text { d'Hebron, Vall d' Hebron Institut of Research (VHIR), CIBERehd. } \\
\text { Universitat Autonoma de Barcelona, Barcelona } \\
\text { Ayuso, Carmen; Hospital Clinic, Radiodiagnostic Resonancia } \\
\text { Bruix, Jordi; Hospital Clinic de Barcelona, Hospital Clínic de Barcelona, } \\
\text { IDIBAPS, CIBERehd, Universitat de Barcelona, Barcelona }\end{array}$ \\
\hline Keywords: & $\begin{array}{l}\text { Early dermatologic reaction; complete radiological response; survival; } \\
\text { sorafenib }\end{array}$ \\
\hline
\end{tabular}




\section{Page 1 of 38}

1

2

3

4

5

6

7

10

11

12

13

14

15

16

17

18

19

20

21

22

23

24

25

26

27

29

30

31

32

33

34

35

36

37

38

39

40

41

42

43

44

45

46

47

48

49

50

51

52

53

54

55

56

57

58

59

60

SCHOLARONE $^{\text {tw }}$
Manuscripts

Hepatology 


\section{Complete response under sorafenib in patients with hepatocellular} carcinoma. Relationship with dermatologic adverse events.

Jordi Rimola ${ }^{1^{*}}$, Álvaro Díaz-González ${ }^{2^{*}}$, Maria Reig ${ }^{2}$, Anna Darnell ${ }^{1}$, María Varela $^{3}$, Fernando Pons ${ }^{4}$, Manuel Hernandez-Guerra ${ }^{5}$, Manuel Delgado ${ }^{6}$, Javier Castroagudin $^{7}$, Ana Matilla ${ }^{8}$, Bruno Sangro ${ }^{9}$, Carlos Rodriguez de Lope ${ }^{10}$, Margarita Sala ${ }^{11}$, Carmen Gonzalez ${ }^{12}$, Carlos Huertas ${ }^{13}$, Beatriz Minguez ${ }^{14}$, Carmen Ayuso ${ }^{1}$, Jordi Bruix ${ }^{2}$.

${ }^{1}$ Barcelona Clinic Liver Cancer (BCLC) Group. Servicio de Radiodiagnóstico. Hospital Clínic de Barcelona. Universitat de Barcelona, Barcelona. ${ }^{2}$ Barcelona Clinic Liver Cancer (BCLC) Group, Liver Unit, Hospital Clínic de Barcelona, IDIBAPS, CIBERehd, Universitat de Barcelona, Barcelona. ${ }^{3}$ Liver Unit, Hospital Universitario Central de Asturias, Oviedo. ${ }^{4}$ Servicio de Digestivo, Hospital Universitario Puerta de Hierro, Madrid. ${ }^{5}$ Liver Unit, Hospital Universitario de las Islas Canarias, Islas Canarias. ${ }^{6}$ Servicio de Digestivo, Hospital Universitario La Coruña, La Coruña. ${ }^{7}$ Servicio de Digestivo, Hospital Clínico Universitario de Santiago, Santiago de Compostela.

${ }^{8}$ Servicio de Digestivo, Hospital General Universitario Gregorio Marañón, Madrid.

95ervicio de Hepatología. Clínica Universidad de Navarra. Pamplona. ${ }^{10}$ Servicio de Digestivo. Hospital Universitario Marqués de Valdecilla. Santander. IDIVAL. 


\author{
${ }^{11}$ Unidad Hepatología, CIBERehd, Servicio de Aparato Digestivo, Hospital \\ Germans Trias i Pujol, Badalona (Barcelona) \\ 12 Servicio de Digestivo- Sección Hepatologia Hospital General Universitario \\ Valencia,Valencia. \\ ${ }^{13}$ Servicio de Digestivo. Hospital Universitari Dr. Josep Trueta. Girona. \\ ${ }^{14}$ Liver Unit, Department of Internal Medicine. Hospital Universitari Vall \\ d'Hebron, Vall d'Hebron Institut of Research (VHIR), CIBERehd. Universitat \\ Autonoma de Barcelona, Barcelona.
}

Authors' email address:

Jordi Rimola: JRIMOLA@clinic.ub.es

Álvaro Díaz-González: DIAZGONZ@clinic.ub.es

María Reig: MREIG1@clinic.ub.es

Anna Darnell: ANDARNEL@clinic.ub.es

María Varela: maria.varela.calvo@gmail.com

Fernando Pons: fponsr@hotmail.com

Manuel Hernández-Guerra: mhernandezguerra@gmail.com

Manuel Delgado: Manuel.Delgado.Blanco@sergas.es

Javier Castroagudin: javier.castroagudin@gmail.com

Ana Matilla: ammatilla@gmail.com

Bruno Sangro: bsangro@unav.es

Carlos Rodríguez de Lope: carlosrdll@gmail.com

Margarita Sala: msala30852@gmail.com

Carmen González: gonzalez car@gva.es

Carlos Huertas: chuertas.girona.ics@gencat.cat 
Beatriz Minguez: bminguez@vhebron.net

Carmen Ayuso: CAYUSO@clinic.ub.es

Jordi Bruix: JBRUIX@clinic.ub.es

* These authors contributed equally to this work.

Key words: Early dermatologic reaction; complete radiological response; survival; sorafenib. 


\section{Corresponding author: Maria Reig}

María Reig, Liver Unit, Barcelona Clinic Liver Cancer (BCLC) Group, Hospital Clinic Barcelona, IDIBAPS, University of Barcelona, Spain. Centro de Investigación Biomédica en Red de Enfermedades Hepáticas y Digestivas (CIBERehd), Spain. Address: BCLC group, Liver Unit, Hospital Clínic, C/Villarroel 170, 08036 Barcelona, Spain. Email: MREIG1@clinic.ub.es

\section{List of abbreviations}

HCC: Hepatocellular Carcinoma. CR: Complete Response.

ECOG-PS: Eastern Cooperative Oncology Group - Performance Status.

CT: Computed Tomography,

MR: Magnetic Resonance.

CEUS: Contrast Enhanced Ultrasound.

DAE60: Dermatologic Adverse Events within the first 60 days.

NF-KB: nuclear factor $\mathrm{kB}$.

TNF- $\alpha$ : Tumor Necrosis Factor $\alpha$.

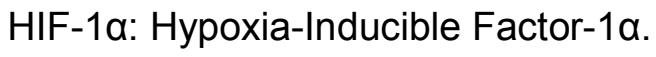

MDSCs: Myeloid-Derived Suppressor Cells.

\section{Financial Support:}

No financial support was obtained for the development of this work. 


\section{Acknowledgments:}

ADG: Received grant support from Instituto de Salud Carlos III, Río Hortega Grant (CM15/00050).

MR: received grant support from Instituto de Salud Carlos III (PI15/00145).

JB: received grant support from Instituto de Salud Carlos III (PI14/00962), AECC (PI044031), Secretaria d'Universitats i Recerca del Departament d'Economia i Coneixement (2014 SGR 605) and WCR (AICR) 16-0026. CIBERehd is funded by the Instituto de Salud Carlos III.

\section{Word count 5992}

3 Tables

\section{Figures}

\section{2 supplementary figures}

\section{1 supplementary table}




\section{Abstract}

Background-aims: The clinical benefit of sorafenib in patients with hepatocellular carcinoma ( $\mathrm{HCC}$ ) has been undervalued due to the absence of complete responses even though patients who develop early dermatologic reactions have shown very positive outcome. In addition, sorafenib is described as an antiangiogenic drug, but it also acts on immunological cells. Thus, the aim is to assess the complete response rate in a retrospective cohort of HCC patients treated with sorafenib and to describe the profile of the patients who achieve complete response in order to identify factors related to this event and their connection with the immunological profile of sorafenib.

Methods: Ten Spanish centres submitted their cases of complete response under sorafenib. The baseline characteristics, development of early dermatologic reactions and cause of treatment discontinuation were annotated. Radiological images pre-sorafenib, at first control, after starting sorafenib, at the time of complete response and at least 1 month after, were centrally reviewed. Results: 20/1119 patients had been classified as complete responders by the centres, but 8 were excluded after central review. Ten patients had complete disappearance of all tumor sites and two had just a small residual fibrotic scar. Thus, 12 patients were classified as complete responders [58\% HCV, median age 59.7 years, $83.4 \%$ Child-Pugh A, ECOG-PS $0 \quad 91.7 \%$ and BCLC-C 83.3\%].Median overall survival and treatment duration were 85.8 and 40.1 months respectively. All but one patient, developed early dermatologic reactions and 7 patients discontinued sorafenib after achieving complete response due to adverse events, patient decision or liver decompensation. 
Conclusion: Complete response affects $1 \%$ of the patients. Its association with early dermatologic reactions supports the role of a specific immune/inflammatory patient profile in the improved response to sorafenib. 


\section{Introduction}

Sorafenib is the first-line systemic treatment for patients diagnosed with hepatocellular carcinoma (HCC). Patients who develop early dermatologic adverse events (eDAE)- defined as dermatological adverse events developed within the first 60 days after starting sorafenib (DAE60)- present better overall survival (OS) than patients who start sorafenib but do not develop these reactions (18.2 months vs 10.1 months; respectively)(1,2). This association can be explained by the biological link between hypoxia (which could be enhanced by sorafenib) and inflammation(3). Thus, even though sorafenib is presented as an anti-angiogenic and anti-proliferative drug, the exact mechanism of action is unknown.

Sorafenib has proven to be effective in patients who may not benefit from options of higher priority such as surgery, ablation or transarterial chemoembolization. However, the clinical benefit of sorafenib treatment for HCC patients is frequently undervalued because the rate of objective response according to conventional criteria(4) is low, both in the pivotal trials $(5,6)$ and in cohort investigations(7-9). By contrast, interventions that reduce tumor burden through resection or induction of tumor necrosis (ablation, chemoembolization, radioembolization) offer such results although they may not offer better survival or may even provide a shorter life expectancy according to published data(10). Interestingly, during the last 9 years several clinical cases and case series of HCC patients have described objective responses under sorafenib and also complete response (CR). These are described in Table 1, but the response criteria used to evaluate the patients in those publications is heterogeneous (RECIST v1.0(11)); RECIST 1.1(4); mRECIST(12) and/or WHO(13). Thus, we 
decided to retrospectively evaluate the rate of $\mathrm{CR}$ under sorafenib in a multicenter study in Spain.

\section{Patients and methods}

This is a multicentre retrospective study including HCC patients treated with sorafenib between October 2007 and March 2014, with the aim of evaluating patients who achieved CR according to RECIST v1.1 plus SHARP trial criteria amendments(14) that were implemented to properly define additional nodules in the setting of cirrhosis and avoid the registration of ascites and pleural effusion as progression if not proven by cytology. We did not consider the use of necrosis as per EASL criteria.

All patients who were treated with sorafenib in each centre regardless of whether they achieved CR or not, represented the initial study cohort. Each centre submitted the cases that had been classified locally as complete responders, but only those patients who were confirmed to have achieved CR after central review were considered in our final cohort population for the study.

The inclusion criteria were: (1) HCC diagnosed by either pathology or by noninvasive criteria according to AASLD guidelines(15) and EASL guidelines(16);

(2) patients under sorafenib treatment or patients who discontinued sorafenib treatment due to adverse events but who had not received an additional treatment after complete radiological response under sorafenib according to RECIST v1.1(4).

The exclusion criteria were: (1) concomitant oncologic treatment prior to CR; (2) Absence of complete radiological response according to RECIST 1.1 criteria $(12,17) ;(3)$ HCC treatment after complete response achieved under sorafenib.

Radiological criteria for baseline assessment and tumor response: 
At the time of diagnosis, HCC lesions were divided as target and non-target lesions following RECIST 1.1 criteria(4). Portal or hepatic vein thrombosis was considered malignant if it was biopsy proven and/or displaying arterial enhancement on either computed tomography (CT), Magnetic Resonance (MR) or contrast enhanced ultrasound (CEUS), and/or if it expanded the diameter of the portal or hepatic vein and had close relation with HCC in the liver parenchyma.

The criteria used for assessing radiological complete response have been summarized before and the two central radiologists validated its presence. Because some patients may present residual lesions after CR we also registered $C R$ when observing 1) the persistence of small $(<2 \mathrm{~cm})$ residual lesion replacing the initial infiltrative HCC showing a scar-like appearance (peripheral, non-arterial enhancement pattern but non- or minimal late enhancement, wedge-shaped and with capsular retraction); or 2) unequivocal reduction of extension and diameter of the thrombus with persistence of a thin residual chronic fibrotic-like hypodense non-enhancing thrombus. Furthermore, to be considered residual these lesions had to remain stable for a period of 2 years, ensuring its non-malignant behavior.

\section{Data collected for the analysis:}

The variables collected for the analysis were baseline demographic patients' characteristics, radiological images at 4 time points (pre-sorafenib, first control after starting sorafenib, at the time of $\mathrm{CR}$ and at least 1 month after $\mathrm{CR}$ to confirm it), presence of dermatologic adverse events within the first 60 days of sorafenib treatment, reason for sorafenib discontinuation and status at the end of follow-up (death/alive). 
The radiologic evaluation including number of lesions, size at each time point and response evaluation according RECIST 1.1(4) was done centrally by 2 independent radiologists with more than 10 years of experience each in the field of HCC (JR and AD).

\section{Endpoints of the study}

The primary end point of this study was to evaluate the rate of $C R$ in this multicentre Spanish cohort and analyze the profile of patients who achieved CR under sorafenib treatment, including the development of EDAE days of treatment) during sorafenib treatment.

\section{Treatment}

The starting sorafenib dose and dose adjustments were done according to the clinical practice recommendations $(15,16,18,19)$ that closely parallel the manufacturer's recommendations.

\section{Statistical analysis}

Categorical variables are described as frequencies and percentages and continuous variables as median and ranges. Survival rates and curves were determined using the Kaplan-Meier method. Last date for data collection was October 14, 2016. Analysis was done censoring survivals at the time of last follow-up or at time of starting an additional HCC treatment. All calculations were done with SPSS package version 22 (SPSS Inc., Chicago, IL).

\section{RESULTS:}

Between October 2007 and March 28, 2014, 1119 HCC patients were treated with sorafenib in 13 referral centres across Spain. Ten of these centres had at least one patient with $\mathrm{CR}$ according to their local radiological evaluation, so that 
twenty patients were initially registered locally as CR. However, 8 patients were excluded either because of lack of fulfilment of diagnostic criteria so no conclusive diagnosis could be done prior to treatment (3 cases), target lesion treated simultaneously with radiofrequency or resection (2 cases) and nonconfirmed $\mathrm{CR}$ at central radiology review according to RECIST 1.1(3 cases) (Figure 1). One of these two patients had iso-enhancing lesions on Magnetic Resonance (MR) dynamic sequences, but lesions were still identified on T2 and pre-gadolinium T1 sequences. The second patient had hypoenhancing lesions on CT scan as an effect of sorafenib and was classified at his centre as complete response because of potential full necrosis and hence, was considered a complete responder when applying the mRECIST criteria. Of the remaining 12 patients, 10 of them had complete resolution of all malignant lesions according to RECIST 1.1 (Figure 2), and two additional patients had one small peripheral residual lesion stable for a period of at least 2 years. At baseline, these patients had large infiltrative tumors measuring $11 \mathrm{~cm}$ and 4,3 $\mathrm{cm}$ with tumoral portal vein thrombosis respectively and, after treatment with sorafenib, imaging displayed small areas (21 and $12 \mathrm{~mm}$ in size) without contrast enhancement that were classified as residual fibrotic areas (Supplementary Figure 1 and supplementary Figure 2).

The baseline characteristics of the 12 patients with confirmed CR are summarized in Table 2. Nine of them were men (75\%) and 3 women $(25 \%)$. Median age was 59.7 years [49.8-78]. The most common cause of underlying liver cirrhosis was Hepatitis C Virus (58.3\%), followed by Hepatitis B Virus (16.7\%), alcohol-induced liver disease $(16.7 \%)$ and other causes $(8.3 \%)$. Liver function was preserved in most of the patients: $83.4 \%$ corresponded to Child- 
Pugh A, 8.3\% were Child-Pugh B and $8.3 \%$ were non-assessable because of absence of cirrhosis. $91.7 \%$ were asymptomatic (ECOG-PS 0 ) and $8.3 \%$ presented mild cancer-related symptoms (ECOG-PS 1). In terms of tumor stage, 2 patients corresponded to BCLC B and 10 to BCLC C (83.3\%). Vascular invasion was identified at CT or MR in $66.7 \%$ of patients, and $16.7 \%$ presented extrahepatic spread.

\section{Radiological evaluation:}

The baseline radiological characteristics of the 12 patients finally included in the study are summarized in Table 3. Five patients had nodular type HCC at baseline, three infiltrative type and the remaining four patients had both infiltrative lesions on one hepatic lobe and nodular type on the other. Among the patients with nodular lesions, the number of lesions in the liver ranged from 0 (extrahepatic metastatic spread) to 8 (median, 1 lesion). The tumor size of nodular lesions ranged from 19 to $75 \mathrm{~mm}$ (median, $32 \mathrm{~mm}$ ).

The seven patients with infiltrative HCC had expansive vein thrombosis whereas in those with nodular type only one patient had portal vein thrombosis. Only two patients had extra-hepatic disease, one with lung metastasis and another one with peritoneal recurrence after surgery on the right subphrenic region after right hepatectomy without residual lesions on the liver. No patient had radiological signs of lymph node invasion according to the criteria used for the SHARP trial(5).

The median time between baseline CT scan and the achievement of radiological CR was 6 months (range 1.4 - 16.1 months).

\section{Analysis according to RECIST 1.1 plus protocol amendment:}


In 2 out of the 20 patients (10\%) initially sent for central evaluation, both central readers identified the presence of small residual scar-like lesions in the subcapsular region of the liver which remained stable over a period of 2 years while the patient was under sorafenib treatment. The first patient had at baseline a nodular lesion of $110 \mathrm{~mm}$ that decreased in size $(21 \mathrm{~mm})$ but persisted as such small lesion together with the presence of new peripheral calcification. The second patient had at baseline a $43 \mathrm{~mm}$ nodular lesion, an infiltrative HCC and an expansive portal vein thrombosis. In addition to the 12 $\mathrm{mm}$ residual scar-like lesion, a residual non-expansive portal vein thrombosis was also identified (Supplementary figure 1 and supplementary figure 2).

According to RECIST 1.1 criteria these patients cannot be classified as CR, but the radiological characteristics and morphological changes of these lesions, and especially their stability over time, favors the classification of these patients as complete responders.

\section{Clinical outcome, treatment duration and overall survival:}

Sorafenib was initiated at full dose (800 mg/day) in the whole cohort except in one patient. His attending physician started at half dose because of concerns about potential interaction with concomitant anticoagulant treatment. All but one $(91.6 \%)$ of the patients developed dermatologic adverse events within the first 60 days of treatment. The patient without early dermatologic adverse events corresponds to the one that initiated sorafenib at half dose.

At the time of CR registration, four patients (33.4\%) were treated at $800 \mathrm{mg}$ per day, one (8.3\%) patient at $600 \mathrm{mg}$ per day, three of them (25\%) at $400 \mathrm{mg}$ per day, one $(8.3 \%)$ at $200 \mathrm{mg}$ per day and three $(25 \%)$ of them were without any kind of treatment due to definitive interruption as per patient decision. 
The median overall survival was 85.8 months (IC 95\% 67.8 - 103.8). Median treatment duration and median time from sorafenib initiation to documented CR was 40.1 months (range 7.6 - 83.6) and 13.3 (range 0.9 - 33.3) respectively. At the end of the follow-up, 4 patients continued on treatment and did not present tumoral recurrence, and 7 discontinued sorafenib after achieving CR (3 due to vascular events, 2 as a result of patient decision and 2 due to liver decompensation). Five of those who discontinued developed HCC recurrence after sorafenib interruption and the other 2 continue under CR. Median time since sorafenib discontinuation and tumoral recurrence was 16.9 months (range 8.5 - 73). Regarding the pattern of recurrence in these patients, one presented extrahepatic spread involving lymph nodes and lung metastasis, another developed intrahepatic spread and tumoral portal vein thrombosis and three of them presented intrahepatic spread. One patient developed HCC recurrence after 28.02 months of achieving CR under sorafenib.

Nine out of the twelve patients had increased AFP baseline levels. In 8 of them the levels returned to normal, while in one case AFP decreased from 3100 $\mathrm{ng} / \mathrm{dL}$ to levels below $150 \mathrm{ng} / \mathrm{dL}$. Regarding the 2 patients with residual fibrotic lesions that would have been registered as CR despite not fully fitting into the RECIST criteria the AFP data were as follows: one of them had increased AFP levels at baseline (155 ng/dL), achieving normalization when complete response was documented $(4.4 \mathrm{ng} / \mathrm{dL})$, and the other patient had normal AFP value at baseline $(6 \mathrm{ng} / \mathrm{dL})$ and AFP levels remained normal when CR was achieved (4 ng/dL). Figure 3 


\section{Discussion:}

This multicentre observational study conducted after a nationwide survey in Spain, which considered 1119 patients treated with sorafenib, describes the clinical and radiological characteristics of $12 \mathrm{HCC}$ patients that achieved $\mathrm{CR}$ while on treatment. It is worth recalling that our cohort includes patients with advanced disease as reflected by their BCLC stage.

The main issue in the CR evaluation is the criteria used for that evaluation. It is already known that the rate of radiological tumour progression in patients under sorafenib or regorafenib is similar between the different criteria used(20-22). However, these criteria differ in the rate of patients classified as $\mathrm{CR}$, partial response or stable disease. Thus, to rule out the risk of a false positive diagnosis of $\mathrm{CR}$ we did a central revision and excluded $15 \%$ of the original cohort (3 out of the 20 patients evaluated) due to non-confirmed CR at central radiology review according to RECIST 1.1 even when considered as complete responders by the local centre.

Complete responses were not registered in the sorafenib pivotal trials $(5,6)$ but several reports have described such positive evolution in a small number of patients (Table 1). Our study offers a $1.07 \%$ CR rate that fits into an event that is not frequent at all, but that may occur in some fortunate individuals. Shiba et al reported a $0.6 \mathrm{CR}$ rate in their countrywide Japanese study including 3047 patients(23).

The main difference between Shiba and our study was the definition of CR. They defined as complete responders patients with absence of contrast uptake within the tumor at dynamic imaging (mRECIST criteria). While necrosis is easy to be recognized after ablation or chemoembolization, it is more challenging and 
controversial to do so when under sorafenib treatment. For these reasons we decided to adhere to RECIST 1.1 and avoid criteria that consider tumor density as a reflection of necrosis. Overall, if we apply the mRECIST definition for CR the prevalence of CR would be higher than it actually is. Indeed, this is one of the controversial points in the Lencioni et al study $(24,25)$.

As is well known, sorafenib is a powerful vasoconstrictor, as is the case with all antiangiogenics and this implies a reduction in hepatic artery blood flow that may result in hypodensity within the tumor nodules. While a correlation between supposed necrosis at radiology after ablation and pathology findings does exist, no such study is available for systemic therapy and specifically, for sorafenib.

In addition to the cases fitting into the RECIST 1.1 definitions, we registered as complete responders 2 additional patients in whom all radiology findings and follow-up monitoring strongly supported the achievement of complete tumor eradication. If these 2 cases were not included, the CR rate would decrease to $0.9 \%$ but still be informative and key to increasing our understanding.

In the present study, in all but one of our patients $(92 \%)$ the clinical record registered the emergence of early dermatologic adverse events. In the study by Shiba et al.(23) the prevalence of dermatologic adverse events in patients with CR was lower (45\%) but still significantly higher than that in those without CR (patients who did not present CR $(3 \% ; p<0.001)$ which means they presented $\mathrm{PR}, \mathrm{SD}$ or progression.

Thus, on-target sorafenib toxicity may have a predominant but underestimated role in the prediction of outcome. In this regard, we reported that the DAE60 is a predictor of better OS and Branco et al externally validated this data. Indeed, the median risk of death reduction in patients who developed eDAE is $42 \%$, 
higher than that reported in the whole cohort of the SHARP trial (35\%). But, the role of the eDAEs is even more important, if we consider the absence of correlation between TTP and OS in the SHARP and Asian Pacific-data. In this regard, the impact of eDAEs is maintained regardless of the radiological tumour progression.

Thus, our results reinforce the association between eDAEs and better outcome but even more important they can be a link between clinical events and the understudied sorafenib mechanism of action.

The mechanism for the benefits associated to dermatologic adverse events is unknown but are very likely related to an immune modulation induced by any of the targets affected by sorafenib. This drug may modulate the stromal cell population and this may prime several molecular events due to direct action or mediated by reduced blood flow reaching tumor cells(26). Hypoxia activates nuclear factor $\mathrm{kB}(\mathrm{NF}-\mathrm{kB})$, which in turn increases the production of tumor necrosis factor $\alpha$ (TNF- $\alpha$ ), a pro-inflammatory cytokine, but simultaneously attenuates apoptosis. Additionally, interactions between hypoxia and inflammation are seen as a regulatory component of NF-kB and of the regulation of hypoxia-inducible factor-1 $\alpha(\mathrm{HIF}-1 \alpha)$ transcription by NF-kB before and during inflammation (3). Thus, members of the NF-kB family of transcription factors regulate inflammation and score the immune responses and tissue homeostasis $(27,28)$. HIF-1a regulates several functions of myeloid-derived suppressor cells (MDSCs) (29) and allows myeloid cells to generate ATP in oxygen-deprived tissues. Lei et al evaluated the change of the peripheral blood immune pattern and its correlation with prognosis in patients with liver cancer treated with sorafenib. They reported a higher ratio of $B$ cells and regulatory $B$ 
cells in PBMC of patients in the response group (SD or CR) than in that of the non-response group(30).

Interestingly, recent phase 1-2 data using different immune modulators blocking immune checkpoints have offered promising data regarding antitumoral activity and primed a major expectancy in the success of such therapies that needs to be confirmed in adequately powered phase 3 trials. In fact, a $2 \%$ rate of complete response has been reported in the still preliminary data with nivolumab in a cohort of 262 patients(31) and 3.3\% (1/30 patients) in HCV, 2.3 $\%$ in HBV (1/43 patients) and $0 \%$ in uninfected patients (0/72 patients)(32), which is very similar to the rate reported in this manuscript.

However, if hope is the driver for decision making, the rate offered by our results and those by Shiba et al(23) should serve to expose that the expectation for long-term disease- free survival is not absent with sorafenib. It could be argued that the complete responses observed could be just spontaneous regressions of HCC as has been published by several authors, us among them(33). The rate is higher than what is observed if summing up all the placebo control arms of the different trials that have been performed in recent years. This exercise shows a $0.008 \%$ rate of complete responses in the placebo arm (supplementary table 1) and hence, the rate under sorafenib appears higher. Furthermore, the same favourable spontaneous evolution could be suggested in those patients with encouraging long-term outcome after resection or TACE.

Our cohort encompasses a heterogeneous group of patients with different radiological patterns of $\mathrm{HCC}$, including nodular, infiltrative or mixed $\mathrm{HCC}$ lesions. Interestingly enough, $66.7 \%$ (8/12) presented expansive portal vein 
thrombosis and 2 out of 12 presented extra-hepatic lesion but this was not a limitation to achieve a CR.

Thus, the main question in clinical practice is whether sorafenib should be stopped upon detection of complete response or if treatment should be kept in place without time limits. There is no answer to this question but our data suggest that clinicians should be very careful and critically assess all aspects. The first issue is to secure that initial diagnosis is $100 \%$ accurate and complete response is reliable. In our study we discarded three cases because of the absence of a target lesion and three additional cases because local readers initially classified them as complete responders. This was due to the application of the mRECIST criteria which have not been validated at all for systemic therapy, and may be faulty to register necrosis. In such cases the follow-up data showed disease progression in the next 3 to 6 months after registering the supposed CR. Hence, it is likely that such assessment was an overestimation. After securing the existence of CR it is important to retain that we had only one recurrence in patients kept under treatment, while recurrence was observed in 5 of the 7 cases in which the drug was interrupted. According to these observations, it seems sound to keep sorafenib in place until intolerance or adverse events promote its interruption.

In summary, our study exposes that around $1 \%$ of the patients with advanced HCC treated with sorafenib achieve a long-lasting complete response as reflected by a complete disappearance of all tumor sites. This is probably mediated through immune reactivation mediated by the drug as reflected by the significant association with the development of dermatologic adverse events. These findings, together with the recent description of high risk of tumor 
recurrence after antiviral therapy, indicate the major role of immune surveillance in cancer control and thus, supports the ongoing investigation in this field in HCC patients. 


\section{References:}

1. Reig M, Torres F, Rodriguez-Lope C, Forner A, LLarch N, Rimola J, et al. Early dermatologic adverse events predict better outcome in HCC patients treated with sorafenib. J. Hepatol. 2014;61:318-24.

2. Branco F, Alencar R, Volt F, Sartori G, Dode A, Kikuchi L, et al. The Impact of Early Dermatologic Events in the Survival of Patients with Hepatocellular Carcinoma Treated with Sorafenib. Ann. Hepatol. 2017;16:0-0.

3. Schwartz RS, Eltzschig HK, Carmeliet P. Hypoxia and Inflammation. N. Engl. J. Med. 2011;364:656-665.

4. Eisenhauer EA, Therasse P, Bogaerts J, Schwartz LH, Sargent D, Ford R, et al. New response evaluation criteria in solid tumours: revised RECIST guideline (version 1.1). Eur. J. Cancer. 2009;45:228-47.

5. Llovet JM, Ricci S, Mazzaferro V, Hilgard P, Gane E, Blanc J-F, et al. Sorafenib in advanced hepatocellular carcinoma. N. Engl. J. Med. 2008;359:378-90.

6. Cheng A-L, Kang Y-K, Chen Z, Tsao C-J, Qin S, Kim JS, et al. Efficacy and safety of sorafenib in patients in the Asia-Pacific region with advanced hepatocellular carcinoma: a phase III randomised, double-blind, placebocontrolled trial. Lancet. Oncol. 2009;10:25-34.

7. Iavarone M, Cabibbo G, Piscaglia F, Zavaglia C, Grieco A, Villa E, et al. Fieldpractice study of sorafenib therapy for hepatocellular carcinoma: a prospective multicenter study in Italy. Hepatology. 2011;54:2055-63.

8. Iavarone M, Cabibbo G, Biolato M, Della Corte C, Maida M, Barbara M, et al. Predictors of survival in patients with advanced hepatocellular carcinoma who permanently discontinued sorafenib. Hepatology. 2015;62:784-91.

9. Marrero JA, Kudo M, Venook AP, Ye S-L, Bronowicki J-P, Chen X-P, et al. Observational registry of sorafenib use in clinical practice across Child-Pugh subgroups: The GIDEON study. J. Hepatol. 2016;65:1140-1147.

10. Reig M, Gazzola A, Di Donato R, Bruix J. Systemic treatment. Best Pract. Res. Clin. Gastroenterol. 2014;28:921-35.

11. Therasse P, Arbuck SG, Eisenhauer EA, Wanders J, Kaplan RS, Rubinstein L, et al. New guidelines to evaluate the response to treatment in solid tumors. European Organization for Research and Treatment of Cancer, National Cancer Institute of the United States, National Cancer Institute of Canada. J. Natl. Cancer Inst. 2000;92:205-16. 
12. Lencioni R, Llovet J. Modified RECIST (mRECIST) Assessment for Hepatocellular Carcinoma. Semin. Liver Dis. 2010;30:052-060.

13. Organization WH. WHO handbook for reporting results of cancer treatment. 1979;

14. Reig M, Darnell A, Forner A, Rimola J, Ayuso C, Bruix J. Systemic Therapy for Hepatocellular Carcinoma: The Issue of Treatment Stage Migration and Registration of Progression Using the BCLC-Refined RECIST. Semin. Liver Dis. 2014;34:444-455.

15. Bruix J, Sherman M. Management of hepatocellular carcinoma: an update. Hepatology. 2011;53:1020-2.

16. EASL-EORTC clinical practice guidelines: management of hepatocellular carcinoma. J. Hepatol. 2012;56:908-43.

17. Choi H, Charnsangavej C, de Castro Faria S, Tamm EP, Benjamin RS, Johnson $\mathrm{MM}$, et al. CT evaluation of the response of gastrointestinal stromal tumors after imatinib mesylate treatment: a quantitative analysis correlated with FDG PET findings. AJR. Am. J. Roentgenol. 2004;183:1619-28.

18. Sorafenib Product Characteristics [Internet]. [cited 2015 Oct 5];Available from: http://www.nexavar.com/home/pdf/SmPC-Jan-2015.pdf

19. Verslype C, Rosmorduc O, Rougier P. Hepatocellular carcinoma: ESMO-ESDO Clinical Practice Guidelines for diagnosis, treatment and follow-up. Ann. Oncol. 2012;23 Suppl 7:vii41-8.

20. Ronot M, Bouattour M, Wassermann J, Bruno O, Dreyer C, Larroque B, et al. Alternative Response Criteria (Choi, European Association for the Study of the Liver, and Modified Response Evaluation Criteria in Solid Tumors [RECIST]) Versus RECIST 1.1 in Patients With Advanced Hepatocellular Carcinoma Treated With Sorafenib. Oncologist. 2014;19:394-402.

21. Gavanier M, Ayav A, Sellal C, Orry X, Claudon M, Bronowicki JP, et al. CT imaging findings in patients with advanced hepatocellular carcinoma treated with sorafenib: Alternative response criteria (Choi, European Association for the Study of the Liver, and modified Response Evaluation Criteria in Solid Tumor (mRECIST)) versus. Eur. J. Radiol. 2016;85:103-12.

22. Bruix J, Qin S, Merle P, Granito A, Huang Y-H, Bodoky G, et al. Regorafenib for patients with hepatocellular carcinoma who progressed on sorafenib treatment (RESORCE): a randomised, double-blind, placebo-controlled, phase 3 trial. Lancet (London, England). 2017;389:56-66.

23. Shiba S, Okusaka T, Ikeda M, Saito H, Ichida T. Characteristics of 18 patients with hepatocellular carcinoma who obtained a complete response after treatment with sorafenib. Hepatol. Res. 2014;44:1268-1276. 
24. Lencioni R, Montal R, Torres F, Park J-W, Decaens T, Raoul J-L, et al. Objective response by mRECIST as a predictor and potential surrogate end-point of overall survival in advanced HCC. J. Hepatol. 2017;

25. Bruix J, Reig M, Sangro B. Assessment of treatment efficacy in hepatocellular carcinoma: response rate, delay in progression or none of them. J. Hepatol. 2017;

26. Chen Y, Huang Y, Reiberger T, Duyverman AM, Huang P, Samuel R, et al. Differential effects of sorafenib on liver versus tumor fibrosis mediated by stromal-derived factor 1 alpha/C-X-C receptor type 4 axis and myeloid differentiation antigen-positive myeloid cell infiltration in mice. Hepatology. 2014;59:1435-1447.

27. Naugler WE, Karin M. NF-kappaB and cancer-identifying targets and mechanisms. Curr. Opin. Genet. Dev. 2008;18:19-26.

28. Vallabhapurapu S, Karin M. Regulation and function of NF-kappaB transcription factors in the immune system. Annu. Rev. Immunol. 2009;27:693-733.

29. Nizet V, Johnson RS. Interdependence of hypoxic and innate immune responses. Nat. Rev. Immunol. 2009;9:609-17.

30. Lei C-J, Liu J-N, Wu R, Long Z-X, Zhang J-Z, Tao D, et al. Change of the peripheral blood immune pattern and its correlation with prognosis in patients with liver cancer treated by sorafenib. Asian Pac. J. Trop. Med. 2016;9:592-596.

31. Ignacio Melero, Bruno Sangro, Thomas Yau, Chiun Hsu, Masa-toshi Kudo, Todd S. Crocenzi T-Y, Kim, Su-pin Choo, Jorg Trojan, Timothy Meyer, Theodore Welling, Winnie Yeo, Akhil Chopra J, Anderson, Christine Delacruz, Lixin Lang, Jaclyn Neely, Hao Tang ABE-K. Nivolumab (Nivo) in Patients (Pts) With Advanced Hepatocellular Carcinoma (HCC): the CheckMate 040 Study. AASLD Congr. 2016;LB-10.

32. B Sangro, T Yau, C Hsu, J Trojan et al. Nivolumab in sorafenib-experienced patients with advanced hepatocellular carcinoma (HCC) with or without chronic viral hepatitis: CheckMate 040 study. In: EASL International Liver Congress. Amsterdam. p. Abstract GS-010.

33. Cabibbo G, Enea M, Attanasio M, Bruix J, Craxì A, Cammà C. A meta-analysis of survival rates of untreated patients in randomized clinical trials of hepatocellular carcinoma. Hepatology. 2010;51:1274-83. 
Figure 1 HCC: Hepatocellular Carcinoma. CR: Complete Response.

\section{Figure 2}

Computed tomography of an ill defined-infiltrative hepatocellular carcinoma located on segments IV and VIII of the liver. The arterial phase (figure 2a) shows areas of heterogeneous enhancement (arrowheads) that displays scattered areas of washout on portal venous phase (arrowheads in figure 2b). There was an expansive portal vein thrombosis, better seen on coronal reconstruction (arrow in figure 2c).

During Sorafenib treatment, the mass has vanished, persisting a wedge-shaped area of arterial enhancement (arrowheads in figure 2d) with no washout related to residual non-expansive portal vein thrombosis (arrow in figure $2 \mathrm{e}$ ).

\section{Figure 3}

AFP evolution before starting sorafenib, at first control, when CR was documented and after achieving CR. 
Table 1: Clinical cases and cohort studies of patients treated with sorafenib who developed complete radiological response.

\begin{tabular}{|c|c|c|c|c|c|c|c|c|c|c|}
\hline Author, Journal \& Year & $\mathrm{n}$ & Etiology & CPS & PVT & M1 & PS & BCLC & $\mathrm{DAE}$ & DAE60 & $\begin{array}{l}\text { Tumor } \\
\text { response } \\
\text { criteria } \\
\end{array}$ \\
\hline So BJ et al. J Hematol Oncol 2008 & 1 & Hemochromatosi & NR & No & Lung & 2 & $\mathrm{D}$ & No & NR & NR \\
\hline Wang SX et al. Target Oncol 2010 & 1 & $\mathrm{HCV}$ & A & Yes & NR & NR & C & No & NR & NR \\
\hline Kudo M et al. Oncology 2010 & 2 & HBV & A & Yes & Lung & NR & NR & NR & NR & Pathologic \\
\hline Chelis L et al. Med Oncol 2011 & 1 & $\mathrm{HBV}+\mathrm{HIV}$ & No LC & No & No & 0 & C & Yes & NR & NR \\
\hline Inuzuka T et al. Oncology 2011 & 1 & $\mathrm{HCV}$ & A & No & Lung & 1 & $\mathrm{C}$ & No & NR & NR \\
\hline Sacco R et al. BMC Gastroenterol 2011 & 1 & $\mathrm{HCV}$ & A & Yes & No & 0 & C & Yes & NR & RECIST \\
\hline $\begin{array}{l}\text { Abbadessa G et al. World J Gastroenterol } \\
2011\end{array}$ & $1^{*}$ & $\mathrm{HCV}$ & A & Yes & NR & 0 & C & Yes & Yes & NR \\
\hline Mizukami H et al. Case Rep Oncol 2012 & 1 & $\mathrm{HCV}$ & NR & No & Lymph & NR & C & Yes & Yes & RECIST \\
\hline Ahn SY et al. Dig Dis Sci 2013 & 1 & $\mathrm{HBV}$ & A & Yes & NR & NR & $\mathrm{C}$ & NR & NR & NR \\
\hline Gerardi A et al.Oncol Lett 2013 & 1 & $\mathrm{HCV}$ & A & Yes & No & NR & C & Yes & NR & RECIST \\
\hline Hagihara A et al.Intern Med 2013 & 1 & $\mathrm{HCV}$ & $\mathrm{B}$ & Yes & Lung & 3 & $\mathrm{C}$ & No & NR & NR \\
\hline Kee KM et al. Onco Targets Ther 2014 & 1 & Cryptogenic & A & Yes & NR & NR & NR & Yes & Yes & mRECIST \\
\hline Shiozawa K et al. Oncol Lett 2014 & 1 & $\mathrm{HCV}$ & A & Yes & NR & NR & C & Yes & Yes & mRECIST \\
\hline Shiba S et al. Hepatol Res 2014 & 18 & $\begin{array}{l}\text { HCV: } 83,3 \% \\
\text { HBV: } 16,7 \%\end{array}$ & $\begin{array}{l}A: 88.8 \% \\
B: 11.2 \% \\
\end{array}$ & $17 \%$ & $44 \%$ ** & $\begin{array}{l}0: 77.8 \% \\
1: 22.2 \%\end{array}$ & NR & $83 \% \%^{*}$ & NR & mRECIST \\
\hline Moroni M et al. Future Oncol 2015 & 1 & $\mathrm{HCV}$ & $\mathrm{A}$ & Yes & No & 0 & C & Yes & NR & NR \\
\hline Shinoda M et al. World J Surg Oncol 2015 & 1 & Cryptogenic & A & Yes & Lung & NR & NR & No & NR & RECIST \\
\hline Azmi AN et al. J Dig Dis 2015 & 1 & $\mathrm{HCV}$ & A & Yes & No & 2 & NR & Sí & NR & NR \\
\hline $\begin{array}{l}\text { Katafuchi E et al. Case Rep Gastroenterol } \\
2015\end{array}$ & 1 & $\mathrm{HCV}$ & A & No & Lung & NR & NR & No & No & RECIST \\
\hline Park JG et al. Clin Mol Hepatol 2015 & 7 & $\begin{array}{c}\text { HBV: } 57.1 \% \\
\text { HCV:28.6\% } \\
\text { OH + HBV: } \\
14.3 \%\end{array}$ & $\begin{array}{l}A: 57.1 \% \\
B: 42.9 \%\end{array}$ & $\begin{array}{c}\mathrm{Y}: 85.7 \\
\% \\
\mathrm{~N}: 14.3 \\
\%\end{array}$ & $\begin{array}{l}Y: 14.3 \% \\
N: 85.7 \%\end{array}$ & 0 & C & No & No & mRECIST \\
\hline $\begin{array}{l}\text { Maida M et al. J Gastrointestin Liver Dis } \\
2016\end{array}$ & 1 & $\mathrm{OH}$ & A & Yes & No & 0 & $\mathrm{C}$ & No & No & $\begin{array}{l}\text { mRECIST+ } \\
\text { RECIST }\end{array}$ \\
\hline Simao A et al.Acta Med Port 2016 & 1 & $\begin{array}{l}\mathrm{OH}+\mathrm{VHB}+ \\
\quad \mathrm{VHC}\end{array}$ & A & Yes & $\begin{array}{l}\text { Lung + } \\
\text { adrenal }\end{array}$ & NR & $\mathrm{C}$ & No & No & mRECIST \\
\hline
\end{tabular}

CPS: Child-Pugh Score. PVT: Portal Vein Thrombosis. PS: Performance Status. DAE: Dermatologic Adverse Events.

EDA: Early Dermatologic Adverse Events. N: Number of patients; BCLC: Barcelona Clinic Liver Cancer; PVT: Portal Vein Thrombosis; PS: Performance Status; HCV: Hepatitis C Virus; HBV: Hepatitis B Virus; HIV: Human Immunodeficiency Virus; RECIST: Response Evaluation Criteria in Solid Tumors; mRECIST: Modified RECIST. LC: Liver Cirrhosis. NR: Not Reported. M1: Metastases. Y: Yes. N: No.

${ }^{*}$ Only in one patient out of four all information was available

**Lymph nodes $22 \%$, lung $39 \%$.

*** $83 \%$ Hand-Foot skin reaction. $34 \%$ rash. $56 \%$ alopecia. 


\section{Table 2: The baseline clinical and biochemistry characteristics of the whole patients.}

\begin{tabular}{|l|l|}
\hline Age, median value [range] (years) & $\mathrm{N}=12$ \\
Men/Women, \% & $59.7[49.8-78]$ \\
Etiology HCV/Alcohol/HBV/Others, \% & $75 / 25$ \\
Child-Pugh A/B/NA, \% & $58.3 / 16.7 / 16.7 / 8.3$ \\
BCLC B/C, \% & $83.4 / 8.3 / 8.3$ \\
ECOG-Peformance Status (0/1) & $16.7 / 83.3$ \\
Macrovascular invasion (Yes/No), \% & $91.7 / 8.3$ \\
Extrahepatic spread (Yes/No), \% & $66.7 / 33.3$ \\
Bilirrubin mg/dL, median value [range] & $16.7 / 83.3$ \\
Albumin g/L, median value [range] & $0.8[0.4-1.3]$ \\
Prothrombin Time, \% [range] & $39.5[32-51]$ \\
Alpha-fetoprotein ng/mL, median value [range] & $95 \%[71-100]$ \\
Alanine aminotransferaseUI/L, median value [range] & $5306.7[6-37452]$ \\
Aspartate aminotransferase UI/L, median value [range] & $55[12-99]$ \\
Alkaline Fosfatase UI/L, median value [range] & $55.5[14-135]$ \\
Gamma Glutamyltranspeptidase UI/L, median value [range] & 65 [30-244] \\
Creatinine mg/dL median value [range] & $0.77[0.5-1.6]$ \\
\hline
\end{tabular}

HCV: Hepatitis C Virus. HBV: Hepatitis B Virus. NA: Not applicable. BCLC: Barcelona Clínic Liver Cancer. ECOG: Eastern Cooperative Oncology Group. 
Table 3a Baseline clinical and radiological characteristics of the patients finally included in the study. Patients with complete disappearance of lesions.

\begin{tabular}{|c|c|c|c|c|c|c|c|c|}
\hline $\begin{array}{l}\text { Number } \\
\text { of patient }\end{array}$ & $\begin{array}{l}\text { Number of } \\
\text { hepatic } \\
\text { lesions }\end{array}$ & HCC type & $\begin{array}{c}\text { Diameter } \\
\text { of the } \\
\text { biggest } \\
\text { measurable } \\
\text { lesion } \\
(\mathrm{mm})\end{array}$ & $\begin{array}{l}\text { Macrovascular } \\
\text { invasion }\end{array}$ & $\begin{array}{l}\text { Extrahepatic } \\
\text { Metastases }\end{array}$ & Child-Pugh & ECOG-PS & $\begin{array}{l}\text { BCLC } \\
\text { Stage }\end{array}$ \\
\hline 1 & 1 & Infiltrative & & Yes & No & B (7 points) & 1 & C \\
\hline 2 & 1 & Infiltrative & & Yes & No & A & 0 & C \\
\hline 3 & 8 & Nodular & 40 & No & No & A & 0 & B \\
\hline 4 & 1 & $\begin{array}{c}\text { Infiltrative } \\
\text { and } \\
\text { nodular }\end{array}$ & 75 & Yes & No & A & 0 & C \\
\hline 5 & 0 & Nodular & 19 & No & Yes (peritoneal) & No cirrhosis & 0 & C \\
\hline 6 & 2 & Nodular & 32 & Yes & No & A & 0 & C \\
\hline 7 & 1 & Nodular & 21 & No & Yes (lung) & $\bar{A}$ & 0 & $C$ \\
\hline 8 & 1 & $\begin{array}{c}\text { Infiltrative } \\
\text { and } \\
\text { nodular }\end{array}$ & 23 & Yes & No & A & 0 & C \\
\hline 9 & 4 & $\begin{array}{c}\text { Infiltrative } \\
\text { and } \\
\text { nodular }\end{array}$ & 20 & Yes & No & A & 0 & C \\
\hline 10 & 1 & Infiltrative & & Yes & No & $\bar{A}$ & 0 & C \\
\hline
\end{tabular}

Table 3b Baseline clinical and radiological characteristics of the patients finally included in the study. Patients with residual scar stable for more than 2 years.

\begin{tabular}{|c|c|c|c|c|c|c|c|c|}
\hline $\begin{array}{c}\text { Number } \\
\text { of patient }\end{array}$ & $\begin{array}{c}\text { Number of } \\
\text { hepatic } \\
\text { lesions }\end{array}$ & HCC type & $\begin{array}{c}\text { Diameter } \\
\text { of the } \\
\text { biggest } \\
\text { measurable } \\
\text { lesion } \\
(\mathbf{m m})\end{array}$ & $\begin{array}{c}\text { Macrovascular } \\
\text { invasion }\end{array}$ & $\begin{array}{c}\text { Extrahepatic } \\
\text { Metastases }\end{array}$ & Child-Pugh & ECOG-PS & $\begin{array}{c}\text { BCLC } \\
\text { Stage }\end{array}$ \\
\hline $\mathbf{1 1}$ & 1 & Nodular & 110 & No & No & A & 0 & B \\
\hline $\mathbf{1 2}$ & 3 & $\begin{array}{c}\text { Infiltrative } \\
\text { and nodular }\end{array}$ & 43 & Yes & No & A & 0 & C \\
\hline
\end{tabular}

BCLC: Barcelona Clínic Liver Cancer. ECOG: Eastern Cooperative Oncology Group. 


\section{Supplementary material:}

\section{Supplementary Figure 1:}
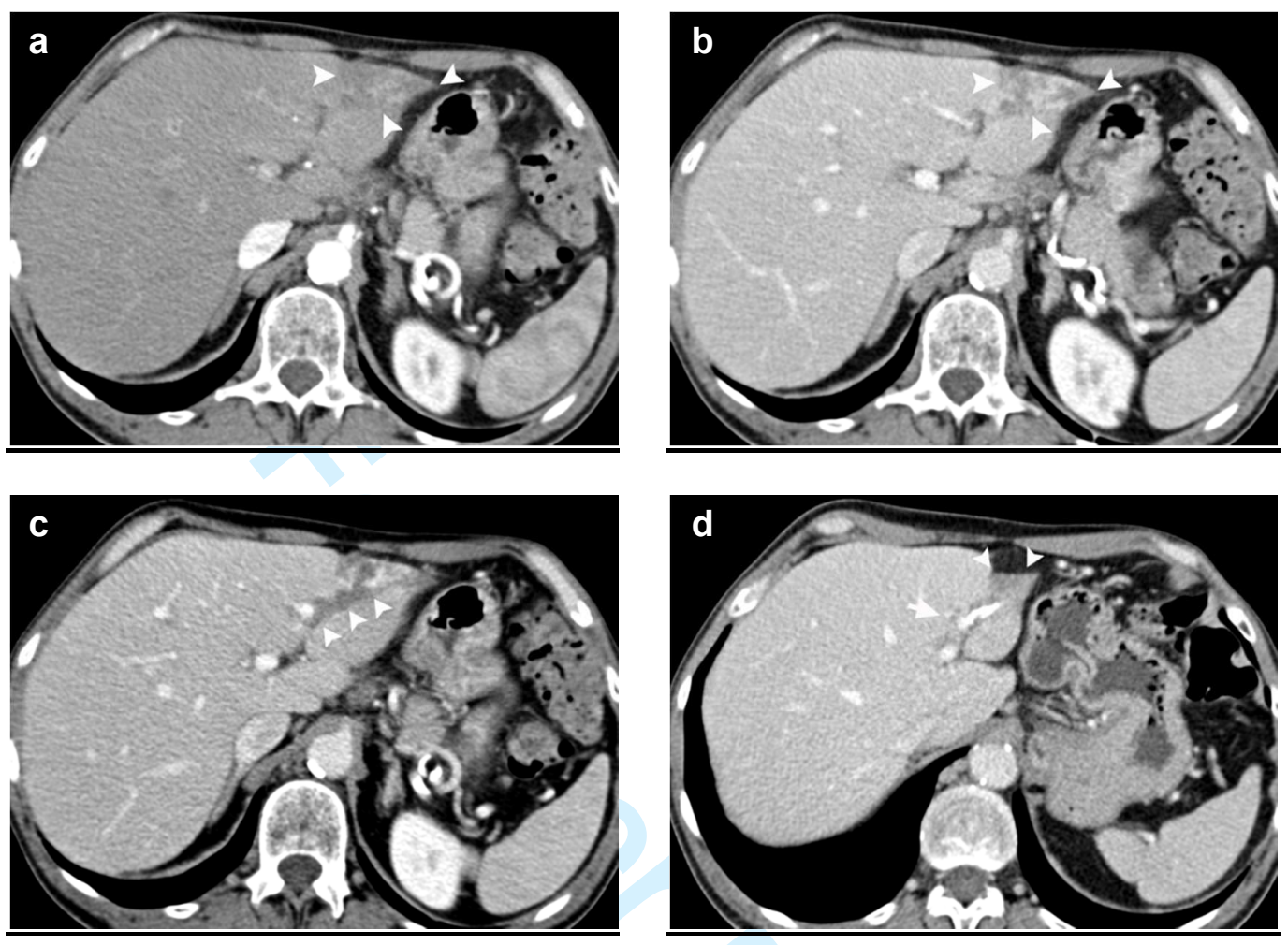


\section{Supplementary Figure 2:}
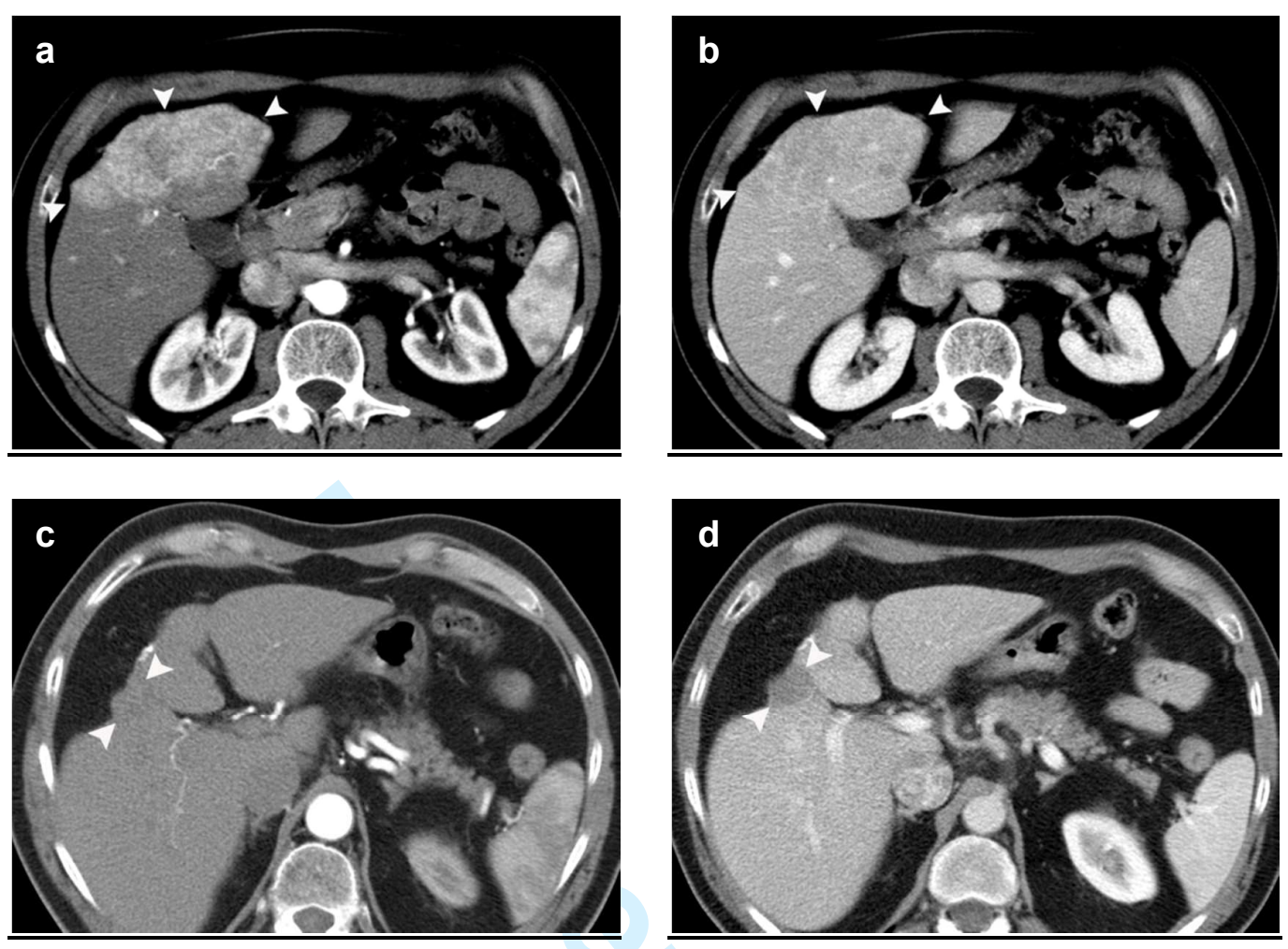

\section{Supplementary Figure 1.}

Computed tomography of a biopsy proven hepatocellular carcinoma. Some heterogeneous arterial enhancing mass (arrowheads in supplementary figure 1a) with no convincing washout (arrowheads in supplementary figure 1a) can be detected on the anterior aspect of the left hepatic lobe. An expansive left portal vein thrombosis can be noted (arrowheads in supplementary figure 1c). After 6 months of Sorafenib treatment, only a residual scar-like $12 \mathrm{~mm}$ in size and a segmental atrophy of left hepatic lobe can be distinguished (arrowheads in supplementary figure 1d). The left portal vein thrombosis was replaced by a linear calcification (arrow in supplementary figure 1d).

\section{Supplementary Figure 2}

Computed tomography of $11 \mathrm{~cm}$ infiltrative hepatocellular carcinoma involving both hepatic lobes. The lesion displays arterial enhancement (arrowheads in supplementary figure 2a) followed by heterogenous washout (arrowheads in supplementary figure 2b). After 2 years of sorafenib, the lesion vanished. A capsular retraction on the previous tumoral area together with a residual $21 \mathrm{~mm}$ size nodular area non-enhancing neither on arterial phase (arrowheads in Supplementary figure 2c) nor in venous phase (arrowheads in supplementary figure 2d) stable over time, were considered residual features. 


\section{Supplementary Table 1:}

\begin{tabular}{|l|l|l|l|}
\hline TRIAL & \multicolumn{1}{|c|}{ AUTHOR } & \multicolumn{1}{c|}{ JOURNAL } & YEAR \\
\hline Tamoxifen vs. placebo & Castells A et al. & Gastroenterology & 1995 \\
\hline Transarterial Embolization vs. placebo & Bruix J et al. & Hepatology & 1998 \\
\hline Interferon vs. placebo & Llovet JM et al. & Hepatology & 2000 \\
\hline Tamoxifen vs. placebo & Liu CL et al. & Am J Gastroenterol & 2000 \\
\hline Transarterial chemoembolization vs. placebo & Lo C et al. & Hepatology & 2002 \\
\hline Octreotide vs. placebo & Yuen M et al. & Hepatology & 2002 \\
\hline Vitamin K3 vs. placebo & Sarin SK et al. & J Gastroenterol Hepatol & 2006 \\
\hline Octreotide vs. placebo & Becker G et al. & Hepatology & 2007 \\
\hline Sorafenib vs. placebo & Llovet JM et al. & N Eng J Med & 2008 \\
\hline Octreotide vs. placebo & Barbare JC et al. & Eur J Cancer & 2009 \\
\hline Sorafenib vs. placebo in Asia-Pacific region & Cheng Al et al. & Lancet Oncology & 2009 \\
\hline Thymostimulin vs. placebo & Dollinger MM et al. & BMC Cancer & 2010 \\
\hline Vandetanib vs. placebo & Hsu C et al. & J Hepatol & 2012 \\
\hline Brivanib vs. placebo & Llovet JM et al. & J Clin Oncology & 2013 \\
\hline Tivantinib vs. placebo & Santoro A et al. & Lancet Oncology & 2013 \\
\hline Everolimus vs. placebo & Zhu AX et al. & JAMA & 2014 \\
\hline Axitinib vs. placebo & Kang Y-K et al. & Ann Oncology & 2015 \\
\hline Ramucirumab vs. placebo & Zhu AX et al. & Lancet Oncology & 2015 \\
\hline Regorafenib vs. placebo & Bruix J et al. & Lancet Oncology & 2016 \\
\hline
\end{tabular}




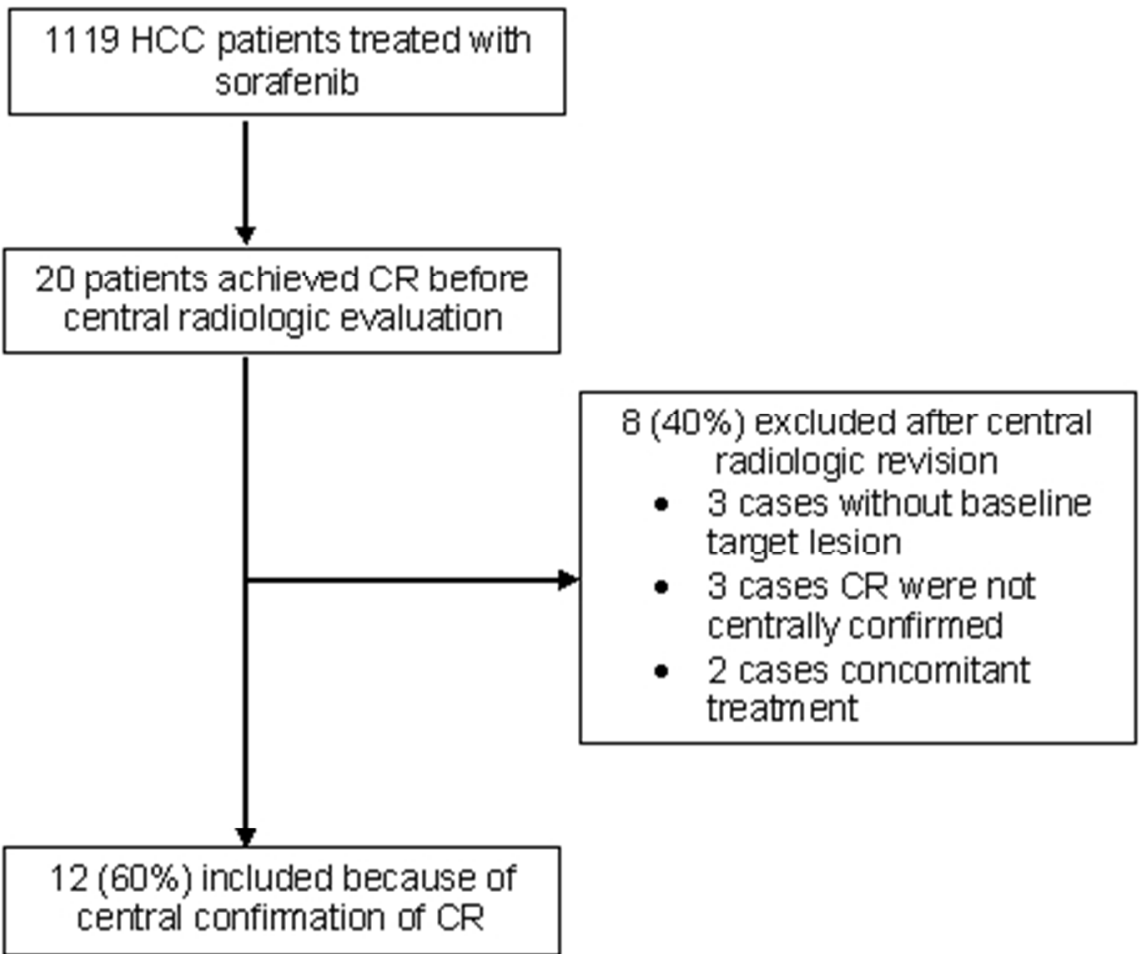

Figure 1 HCC: Hepatocellular Carcinoma. CR: Complete Response.

$116 \times 97 \mathrm{~mm}(96 \times 96 \mathrm{DPI})$ 


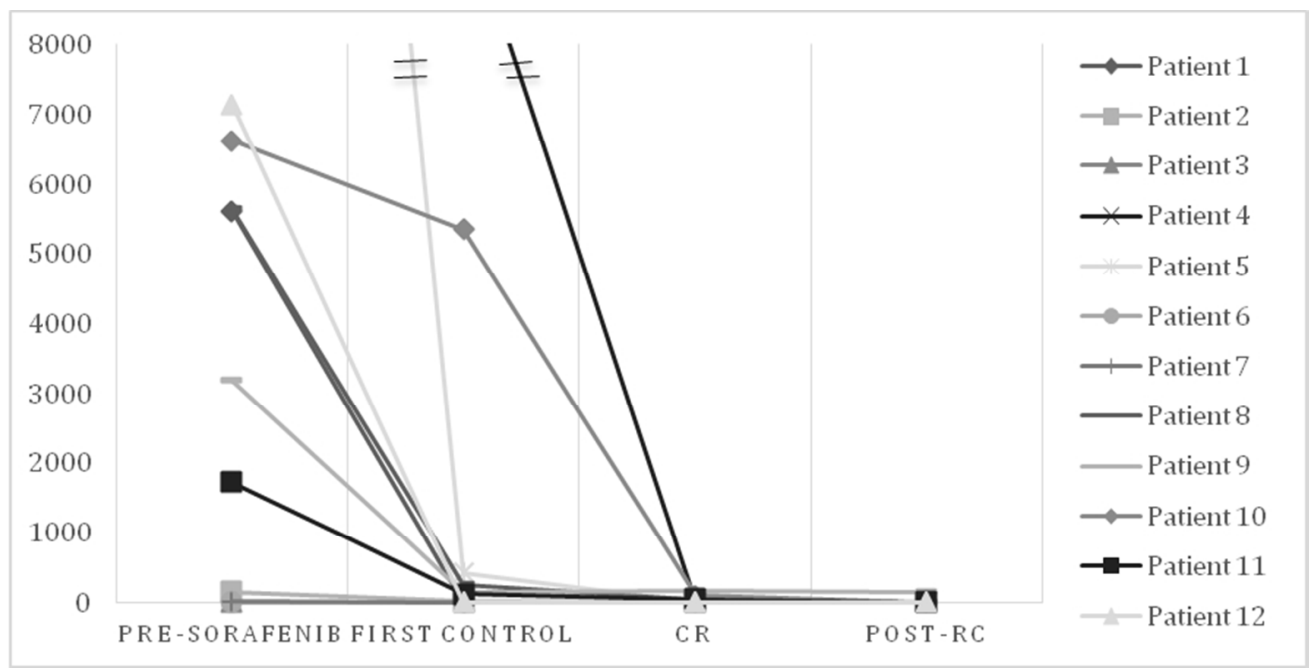

Figure 3: AFP evolution before starting sorafenib, at first control, when CR was documented and after achieving $\mathrm{CR}$.

$235 \times 118 \mathrm{~mm}(96 \times 96 \mathrm{DPI})$ 
Computed tomography of an ill defined-infiltrative hepatocellular carcinoma located on segments IV and VIII of the liver. The arterial phase (figure $2 \mathrm{a}$ ) shows areas of heterogeneous enhancement (arrowheads)

$70 \times 50 \mathrm{~mm}(300 \times 300$ DPI $)$ 


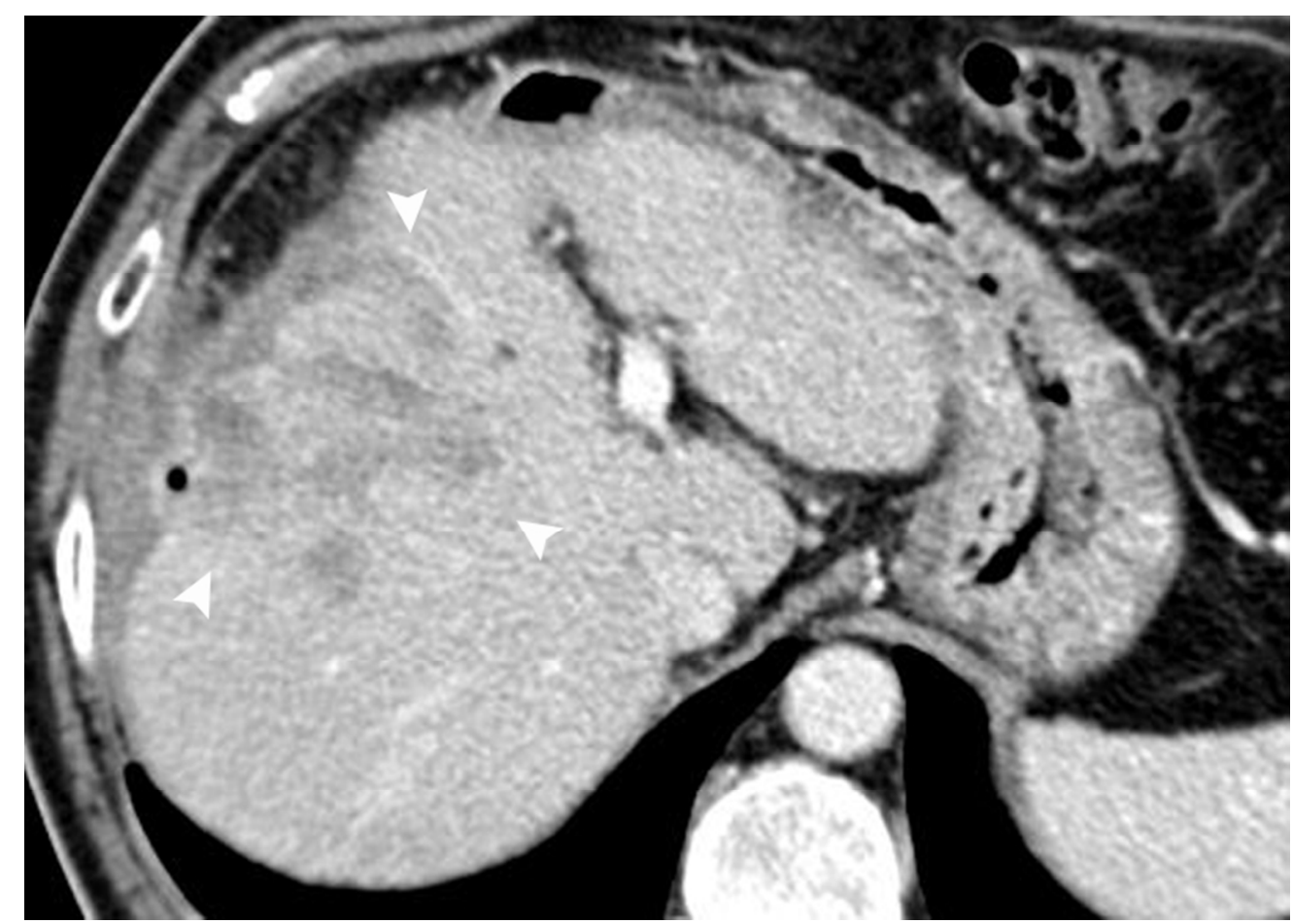

that displays scattered areas of washout on portal venous phase (arrowheads in figure $2 b$ ). $70 \times 50 \mathrm{~mm}(300 \times 300 \mathrm{DPI})$ 


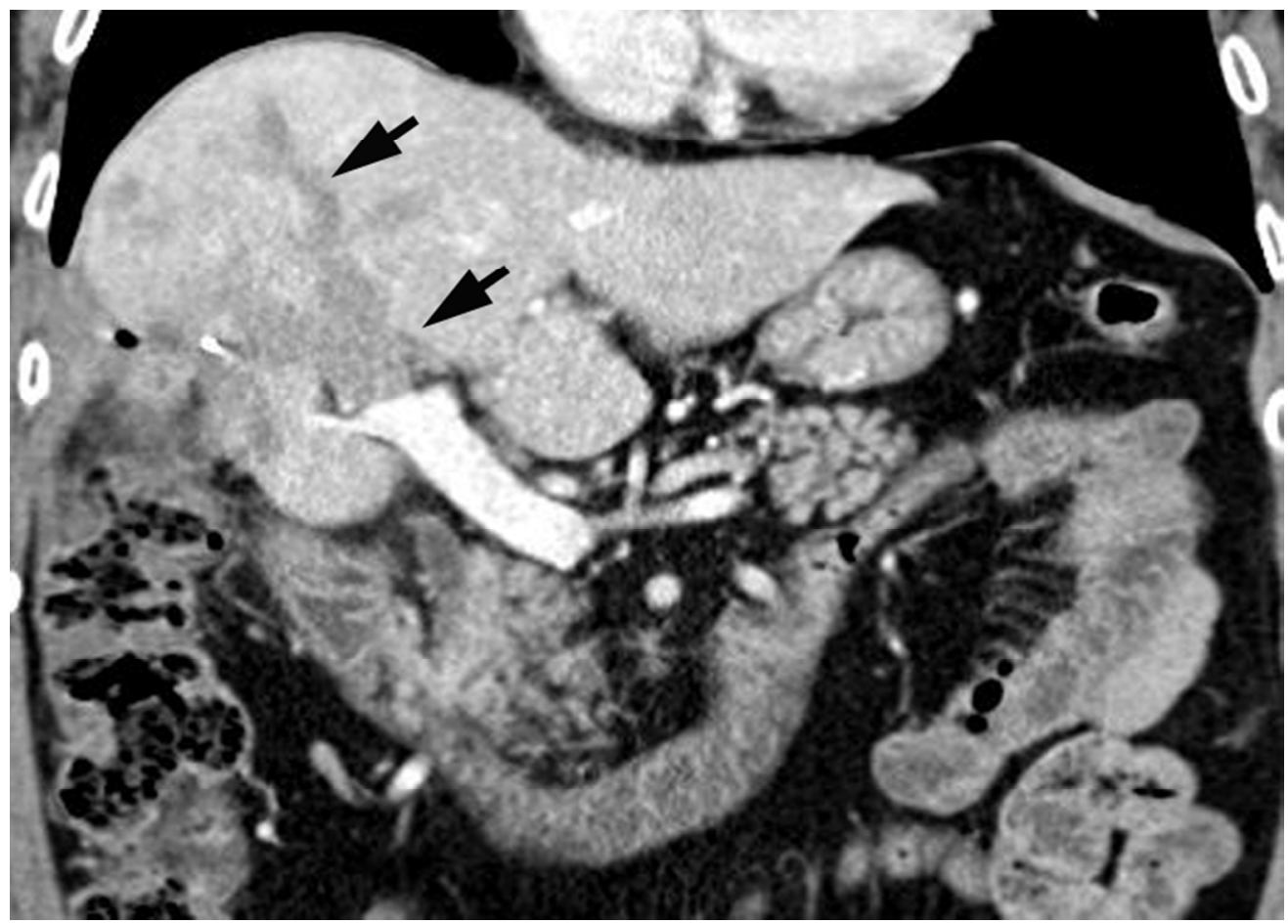

There was an expansive portal vein thrombosis, better seen on coronal reconstruction (arrow in figure $2 \mathrm{c}$ ). $70 \times 50 \mathrm{~mm}(300 \times 300$ DPI $)$ 


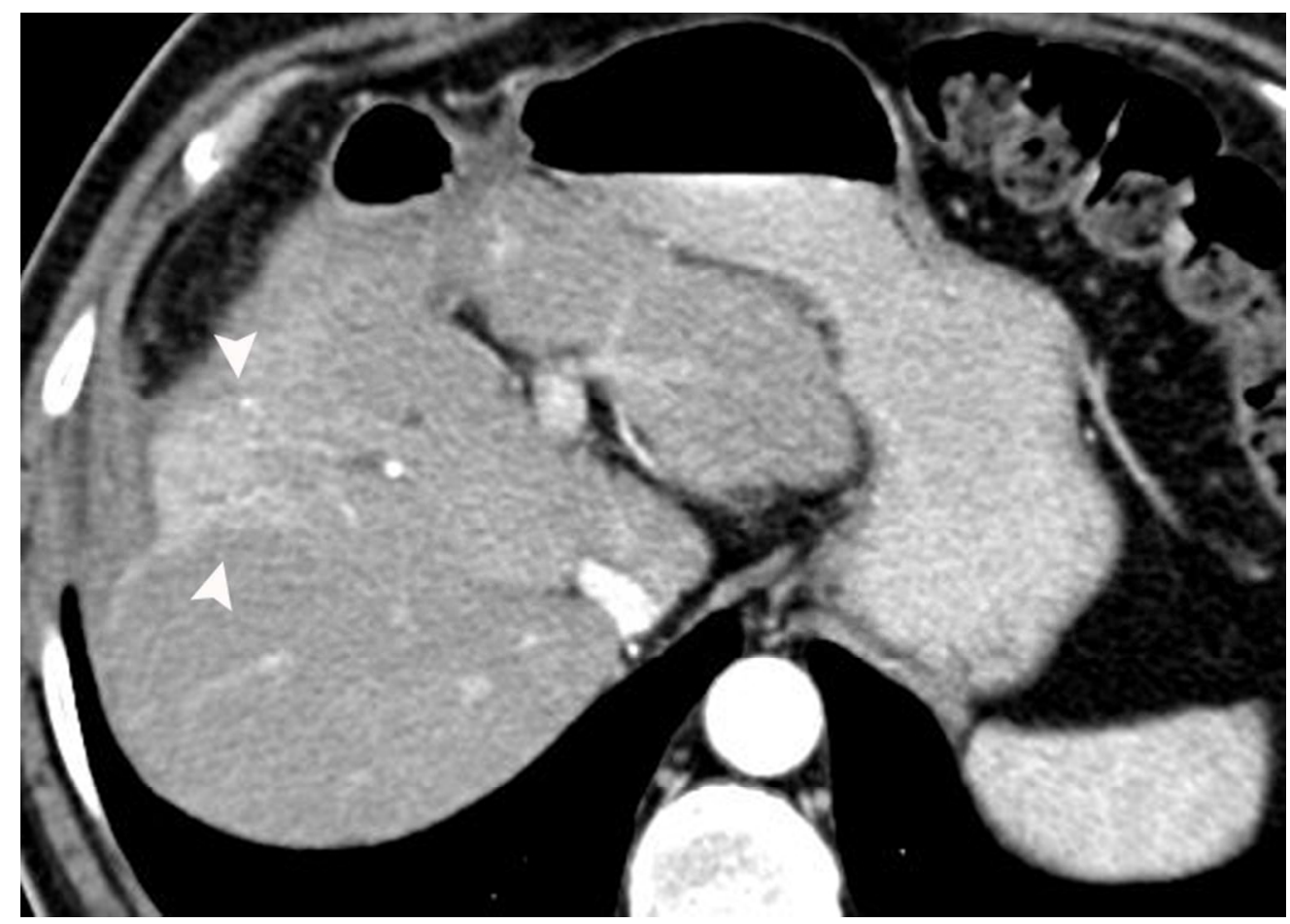

During Sorafenib treatment, the mass has vanished, persisting a wedge-shaped area of arterial enhancement (arrowheads in figure $2 d$ )

$70 \times 50 \mathrm{~mm}(300 \times 300$ DPI $)$ 


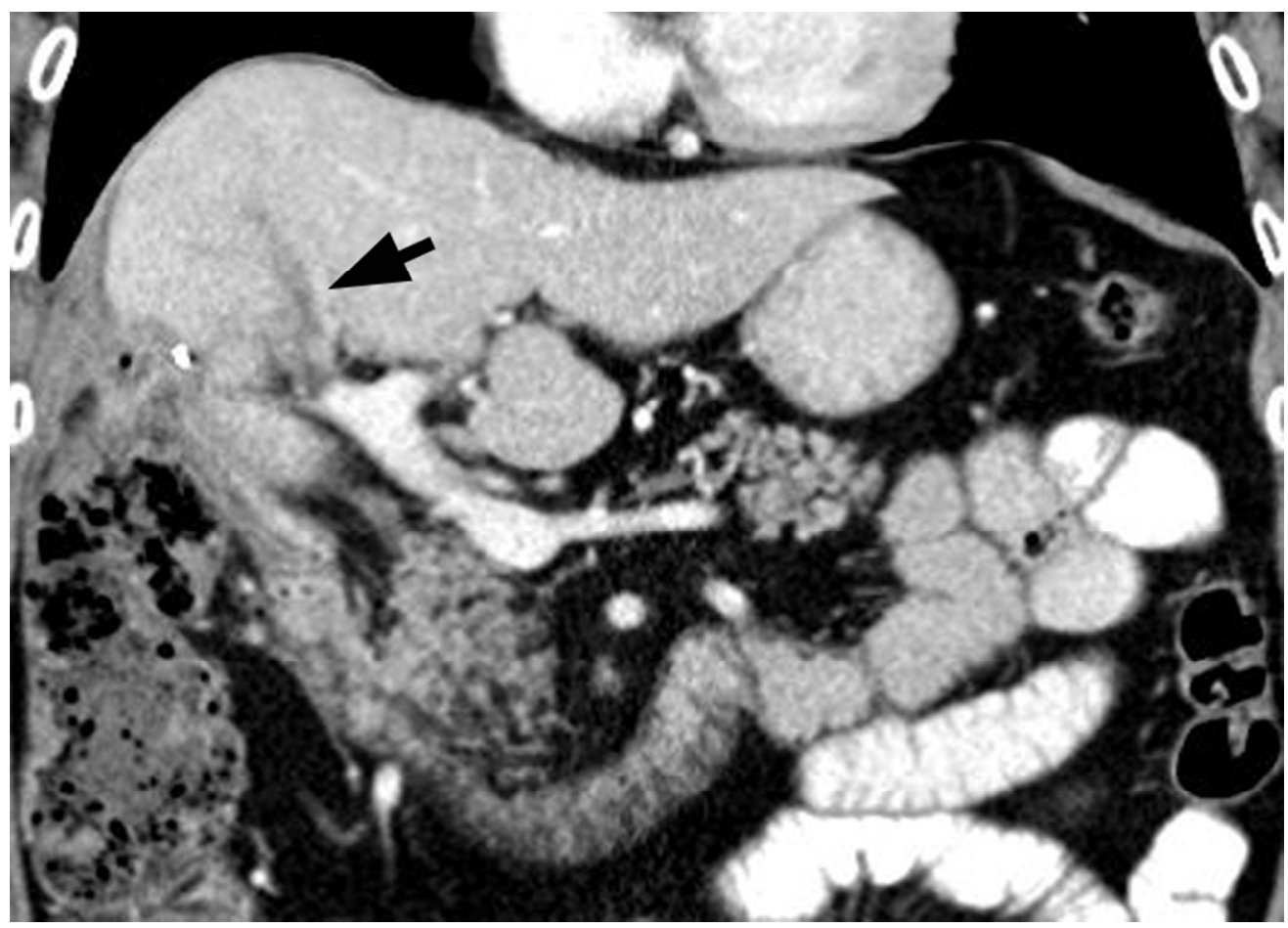

with no washout related to residual non-expansive portal vein thrombosis (arrow in figure 2e). $70 \times 50 \mathrm{~mm}(300 \times 300$ DPI $)$ 